\title{
ANATOMIA DA MADEIRA DE CAMPOMANESIA RHOMBEA O. BERG (MYRTACEAE) $)^{1}$
}

\section{SIDINEI RODRIGUES DOS SANTOS² JOSÉ NEWTON CARDOSO MARCHIORI ${ }^{3}$}

\section{RESUMO}

No presente estudo são descritos, ilustrados e discutidos os caracteres anatômicos do lenho de Campomanesia rhombea O. Berg, com base em material procedente do Rio Grande do Sul. Dos caracteres anatômicos observados, salientam-se para a identificação da espécie: raios heterogêneos relativamente largos (1-4 células), com margens unisseriadas geralmente mais curtas do que o corpo central; parênquima axial difuso-emagregados, tendente a escalariforme; séries parenquimáticas com 2-4 células de altura; vasos com frequiência de $17 / \mathrm{mm}^{2}$ e diâmetro médio de $70 \mu \mathrm{m}$.

Palavras-chave: Campomanesia rhombea, anatomia da madeira, Myrtaceae.

\section{ABSTRACT}

[Wood anatomy of Campomanesia rhombea O. Berg (Myrtaceae)].

The anatomical features of the wood of Campomanesia rhombea O. Berg are presently described, based on material from Rio Grande do Sul state - Brazil. The most important features to the species recognition include: heterogeneous, relatively wide rays (1-4 cells), with uniseriate margins commonly shorter than the central body; axial parenchyma diffuse-in-aggregates, tending to scalariform pattern; parenchyma strands with 2-4 cells; and pores with $70 \mu \mathrm{m}$ width, in frequency of $17 / \mathrm{mm}^{2}$.

Key words: Campomanesia rhombea, wood anatomy, Myrtaceae.

\section{INTRODUÇÃO}

Com cerca de 150 gêneros e 3600 espécies, a família Myrtaceae é uma das mais importantes em diversidade nos trópicos, inclusive no Brasil, onde são encontradas aproximadamente 1200 espécies, todas da tribo Myrteae (Govaerts et al., 2008). Apesar da importância, são escassos os estudos sobre a anatomia de madeiras nativas da família, fato que pode ser explicado, em parte, pelo elevado número de espécies, pela complexidade taxonômica do grupo, pelas di-

1 Recebido para publicação em 19/10/2010 e aceito para publicação em 05/11/2010.

2 Biólogo, bolsista (CNPq - Brasil), doutorando do Programa de Pós-Graduação em Engenharia Florestal, Departamento de Ciências Florestais, Universidade Federal de Santa Maria, CEP 97105-900, Santa Maria, RS, Brasil. sthurt.bio@gmail.com

3 Engenheiro Florestal, Dr. Bolsista de Produtividade em Pesquisa (CNPq - Brasil). Professor Titular do Departamento de Ciências Florestais, Universidade Federal de Santa Maria, Santa Maria, RS, Brasil. mensões geralmente reduzidas dos troncos, fator que desestimula a utilização dos mesmos para fins mais nobres, bem como pelo uso tradicional de outras madeiras (Ovando et al., 2010).

Pertencente a tribo Myrteae (ou subfamília Myrtoideae), o gênero Campomanesia está representado no Rio Grande do Sul por seis espécies de árvores e arbustos (Sobral, 2003), todas de escassa importância sob o ponto de vista da utilização, com exceção de Campomanesia xanthocarpa, frutífera bastante conhecida.

Campomanesia rhombea, objeto do presente estudo anatômico, é arvoreta de 3-8 m de altura, de casca exfoliante e folhas membranáceas, elípticas ou obovadas, de bordo ondulado e largura geralmente inferior a $15 \mathrm{~mm}$ (Sobral, 2003).

Popularmente conhecida por guabiroba-miúda, a espécie ocorre naturalmente de Minas Gerais ao Rio Grande do Sul, participando, neste Estado, da Floresta Ombrófila Mista do Planal- 
to e Campos de Cima da Serra, da Floresta Atlântica e, especialmente, da Floresta Estacional da Depressão Central (Sobral, 2003).

O presente estudo tem por objetivo a descrição microscópica da madeira de Campomanesia rhombea, com vistas a contribuir para o maior conhecimento estrutural das Myrtaceae nativas.

\section{REVISÃO DE LITERATURA}

A literatura dispõe de escassas referências anatômicas sobre os representantes do gênero Campomanesia.

Das espécies nativas no Estado, constam referências sobre a anatomia da madeira de Campomanesia guazumifolia (Marchiori, 1998), Campomanesia xanthocarpa (Santos \& Marchiori, 2009) e Campomanesia aurea (Marchiori \& Santos, 2010). Entre as principais características observadas, citam-se: poros exclusivamente solitários; elementos vasculares de comprimento médio, com placas de perfuração simples; parênquima predominantemente apotraqueal difuso-em-agregados; raios heterogêneos com 3 ou mais células de largura e margens relativamente curtas; fibras com pontoações areoladas; e ausência de cristais. Salientam-se, além disso, a baixa freqüência e o grande diâmetro de poros, bem como a baixa frequiência de raios, aspectos, todavia, nem sempre presentes. Para Campomanesia xanthocarpa, Rodrigues (2005) fornece uma descrição microscópica de, mas com base em amostras de lenho juvenil, proveniente do Estado do Paraná.

Para o gênero em estudo, Metcalfe \& Chalk (1972) relacionam: poros em número de 5-20/ $\mathrm{mm}^{2}$; vasos solitários, de diâmetro médio e em linhas oblíquas frouxas; e raios heterogêneos com 4 - 6 células de largura e 1 - 3 fileiras marginais de células quadradas e eretas.

\section{MATERIAL E MÉTODOS}

A descrição anatômica baseou-se em uma amostra de madeira, coletada na Floresta Nacional (FLONA) de São Francisco de Paula, Rio Grande do Sul. A amostra e respectivas exsicatas botânicas foram incorporados à Xiloteca e Herbário do Departamento de Ciências Florestais da Universidade Federal de Santa Maria (HDCF), sob o número 6148.

Do material lenhoso foram extraídos três corpos de prova $(1 \times 2 \times 3 \mathrm{~cm})$ da parte mais externa do lenho, próxima ao câmbio, orientados para obtenção de cortes nos planos transversal, longitudinal radial e longitudinal tangencial. Outro bloquinho foi também retirado, com vistas à maceração.

A confecção das lâminas histológicas seguiu a metodologia descrita em Burger \& Richter (1991). As lâminas de macerado foram obtidas de acordo com o método de Franklin, modificado (Kraus \& Arduin, 1997). Os cortes anatômicos foram tingidos com safra-blau; o macerado, apenas com safranina (1\%). A montagem das lâminas permanentes foi feita com Entellan.

A descrição baseou-se nas recomendações do IAWA Committee (1989). No caso da percentagem dos tecidos, foram realizadas 600 determinações ao acaso, com auxílio de contador de laboratório, conforme proposto por Marchiori (1980). A freqüência de poros foi obtida de forma indireta, a partir de um quadrado de área conhecida superposto a fotomicrografias de seções transversais da madeira.

As medições foram realizadas em microscópio Carl Zeiss, no Laboratório de Anatomia da Madeira da Universidade Federal de Santa Maria. Nas características quantitativas, os números entre parênteses equivalem aos valores mínimos e máximos observados; o valor que acompanha a média é o desvio padrão. As fotomicrografias foram tomadas em microscópio Olympus CX40, equipado com câmera digital Olympus Camedia c3000, no Laboratório de Anatomia da Madeira da Universidade Federal do Paraná, a quem os autores agradecem.

\section{DESCRIÇÃO ANATÔMICA}

Anéis de crescimento: distintos, delimitados por fina camada de fibras radialmente estreitas no lenho tardio, bem como pela presença de 
zonas fibrosas no limite do anel de crescimento (Figura 1A,B).

Vasos: pouco numerosos a numerosos $(17 \pm$ $5,2(12-25)$ poros $\left./ \mathrm{mm}^{2}\right)$, ocupando $5 \pm 1,4 \%$ do volume da madeira. Porosidade difusa. Poros exclusivamente solitários, circulares a ovais, pequenos $(70 \pm 15,5(35-92,5) \mu \mathrm{m})$, de paredes espessas $(4,1 \pm 0,77(2,5-5) \mu \mathrm{m})$ e sem padrão definido de organização (Figura 1A,B). Elementos vasculares de comprimento médio $(392 \pm 82,5(180-500 \mu \mathrm{m})$, com placas de perfuração simples, ligeiramente oblíquas (Figura 1D), e apêndices presentes, em uma ou em ambas as extremidades, ou então, menos comumente, ausentes. Pontoações intervasculares alternas, circulares $(5,9 \pm 0,36(5,1-$ 6,2) $\mu \mathrm{m}$ ), com abertura em fenda inclusa, ornamentada. Pontoações raio-vasculares com aréolas distintas, semelhantes às intervasculares, porém menores $(2,8 \pm 0,27(2,6-3,1) \mu \mathrm{m}) \mathrm{e}$ restritas às margens de raios. Espessamentos espiralados, ausentes. Conteúdo avermelhado, escasso.

Parênquima axial: muito distinto das fibras em corte transversal, representando $19 \pm 4,8 \%$ do volume da madeira; em arranjo apotraqueal difuso e, principalmente difuso-em-agregados, além de paratraqueal escasso. As células de parênquima formam linhas tangenciais onduladas e mais ou menos regularmente distribuídas, compondo um padrão quase escalariforme (Figura 1A,B). Séries parenquimáticas com (2) 4 células, medindo $404 \pm 62,8(200-510) \mu \mathrm{m}$ de altura (Figura 1E).

Raios: ocupando $14 \pm 2,7 \%$ do volume da madeira, numerosos a muito numerosos (13 \pm $1,2(10$ - 14) raios/mm), com 1 - 3 (raro 4) células de largura e tendendo a organizar-se em dois tamanhos distintos, devido à escassez dos bisseriados (Figura 1E). Raios multisseriados com $244 \pm 41,6(170-330) \mu \mathrm{m}$ e $10-20$, mais comumente 11 - 17 células de altura; heterogêneos, reúnem células procumbentes na parte multisseriada e (1) 2 - 5 fileiras marginais de células quadradas, eretas e procumbentes mais altas do que as do corpo central (Figura 1C). As margens unisseriadas são geralmente mais curtas do que o corpo central (Figura 1E,F). Os unisseriados medem $103 \pm 44,1(30-210) \mu \mathrm{m}$ e 1 - 6 células de altura. Raios axialmente fusionados, escassos. Células radiais de paredes disjuntas, presentes. Células envolventes, células perfuradas e conteúdos, ausentes.

Fibras: representando $62 \pm 5,8 \%$ do volume da madeira, com pontoações areoladas e aberturas cruzadas, presentes nas faces radiais e tangenciais da parede (Figura 1F); de comprimento médio $(1140 \pm 91,5(1000-1380) \mu \mathrm{m})$, com 15,8 $\pm 1,3(13,7-18,7) \mu \mathrm{m}$ de largura e paredes finas a espessas $(5,2 \pm 0,57(4,4-6,2)$ $\mu \mathrm{m})$ (Figura 1B). Fibras septadas, fibras gelatinosas e espessamentos espiralados, ausentes. Traqueídeos vasicêntricos, presentes.

Outros caracteres: variantes cambiais, tubos laticíferos e taniníferos, canais intercelulares, máculas, células oleíferas ou mucilaginosas, estratificação e cristais, ausentes.

\section{ANÁLISE DA ESTRUTURA ANATÔMICA}

As principais características anatômicas observadas na madeira de Campomanesia rhombea são compatíveis com as possibilidade estruturais referidas para a família Myrtaceae e gênero Campomanesia, por Record \& Hess (1949) e Metcalfe \& Chalk (1972). Entre os aspectos mais importantes, destacam-se: poros exclusivamente solitários, de diâmetro grande e pouco frequentes; parênquima predominantemente apotraqueal, em linhas distribuídas mais ou menos regularmente, lembrando o padrão escalariforme; séries parenquimáticas com 2-4 células de altura; e raios relativamente largos (até 4 células), de corpo multisseriado mais alto do que as margens unisseriadas, tendendo a organizar-se em dois tamanhos distintos.

Embora não exclusiva de Campomanesia, a presença de raios relativamente largos (3 ou mais células) é a única característica de valor diagnóstico compartilhada pelas demais espécies do gênero referidas na literatura. Metcalfe 


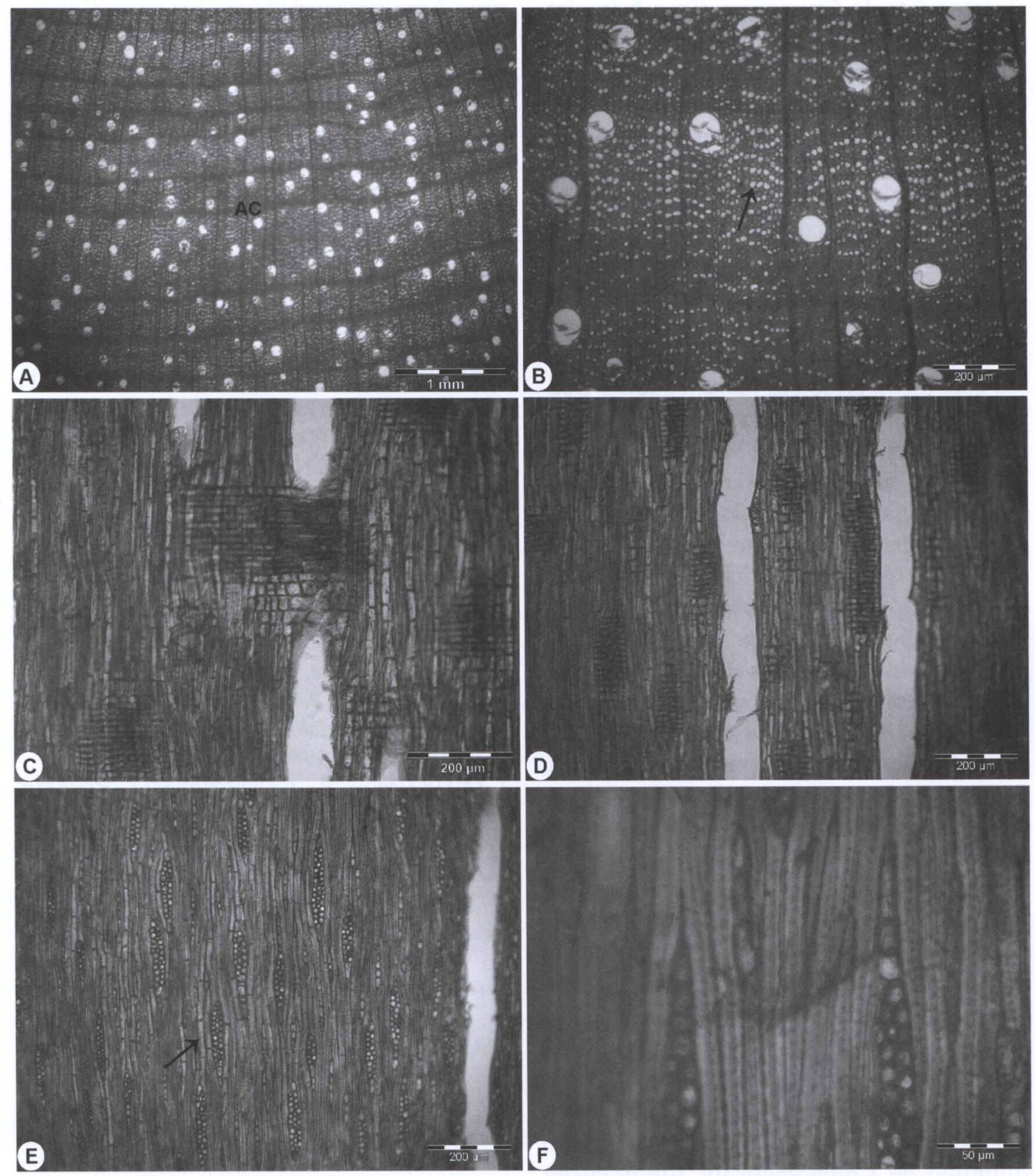

FIGURA 1 - Fotomicrografias da madeira de Campomanesia rhombea. A - Seção transversal, mostrando limite de anel de crescimento com zonas fibrosas conspícuas (AC), porosidade difusa e poros exclusivamente solitários, sem padrão definido de organização. B - Mesma seção, com maior aumento, mostrando poros circulares e parênquima apotraqueal, em linhas regularmente distribuídas, tendentes ao padrão escalariforme (seta). C - Raio heterogêneo, com células procumbentes (no corpo) e margens de células quadradas, eretas e procumbentes (seção longitudinal radial). D - Vasos com placas de perfuração simples ligeiramente oblíquas, em seção radial. E - Seção longitudinal tangencial, mostrando raios com 1-3 células de largura e série de parênquima axial (seta). F - Mesma seção, em maior aumento, destacando fibras com pontoações areoladas e raio com margens unisseriadas mais curtas do que o corpo central multisseriado. 
\& Chalk (1972) também reconhecem como característico de Campomanesia, a baixa freqüência de poros $\left(<20 / \mathrm{mm}^{2}\right)$ e a presença de vasos de diâmetro médio. Apesar do presente estudo corroborar esta generalização, mesmo assim ela parece inadequada, posto que certas espécies do gênero, caso de Campomanesia guazumifolia (Marchiori, 1998) e Campomanesia aurea (Marchiori \& Santos, 2010), apresentam valores que ultrapassam os acima referidos.

Para o gênero Campomanesia, Metcalfe \& Chalk (1972) referem, ainda, a presença de vasos com distribuição em linhas oblíquas frouxas, padrão distinto do observado na espécie em estudo. Marchiori (1998) e Marchiori \& Santos (2010), por sua vez, também não mencionam esta tendência de distribuição de poros nas madeiras do gênero por eles investigadas.

Além destas características, foram também observados: elementos vasculares de comprimento médio; placas de perfuração simples; pontoações intervasculares alternas e ornamentadas; fibrotraqueídeos de comprimento médio; presença de traqueídeos vasicêntricos; e ausência de cristais e de espessamentos espiralados. Todos estes aspectos, segundo Vliet \& Baas (1984), apresentam ampla ocorrência em Myrtaceae.

No tocante aos caracteres anatômicos diferenciais para as espécies nativas de Campomanesia, salientam-se: a frequência e diâmetro de poros; a presença ou não de espessamentos espiralados; a largura de raios; o arranjo e a altura das séries de parênquima axial; e o comprimento de fibras.

Resta salientar que Campomanesia rhombea é, por vezes, referida na literatura botânica como sinônimo de Campomanesia xanthocarpa (Landrum, 1986). A análise comparativa da estrutura anatômica das duas espécies, todavia, não corrobora tal posicionamento. Foram observadas diferenças anatômicas importantes, que justificam a manutenção das mesmas como entidades taxonômicas distintas, em concordân- cia com a interpretação de Sobral (2003), feita com base na morfologia externa: Campomanesia xanthocarpa apresenta raios mais largos (1-4 (até 5) células de largura) e séries parenquimáticas mais altas (4-5 (até 8) células de altura) do que Campomanesia rhombea, que tem raios com 1-3 (raro 4) células de largura e séries de parênquima de até 4 células.

\section{REFERÊNCIAS BIBLIOGRÁFICAS}

BURGER, L.M., RICHTER, H.G. Anatomia da Madeira. São Paulo: Ed. Nobel, 1991. 154 p.

GOVAERTS, R.; SOBRAL, M.; ASHTON, P.; BARRIE, F.; HOLST, B.K.; LANDRUM, L.; MATSUMOTO, K.; MAZINE, F.F.; LUGHADHA, E.N.; PROENÇA, C.; SILVA, L.H.S.; WILAON, P.; LUCAS, E. World Checklist of selected plant families - Myrtaceae. Kew Publishing, Royal Botanic Gardens, Kew. 2008.

IAWA COMMITTEE. IAWA list of microscopic features for hardwood identification. IAWA Bulletin, v.10, n. 3, p.218-359, 1989.

KRAUS, J.E.; ARDUIN, M. Manual básico de métodos em morfologia vegetal. Rio de Janeiro: EDUR, 1997. 198 p.

LANDRUM, L.R. Campomanesia, Pimenta, Blepharocalyx, Legrandia, Acca, Myrrinium and Luma. Flora Neotropica, n. 45, p .1-178, 1986.

MARCHIORI, J.N.C. Estudo anatômico do xilema secundário de algumas espécies dos gêneros Acacia e Mimosa, nativas no Estado do Rio Grande do Sul. 1980. 186f. Dissertação (Mestrado em Engenharia Florestal) - Universidade Federal do Paraná, Curitiba, 1980.

MARCHIORI, J.N.C. Estudo microscópico da madeira de sete-capotes, Campomanesia guazumifolia (Camb.) Berg. (Myrtaceae). Ciência Rural, Santa Maria, v. 28, n. 1, p. 47-51, 1998.

MARCHIORI, J.N.C.; SANTOS, S.R. Anatomia das madeiras de Campomanesia aurea $\mathrm{O}$. Berg e Eugenia myrcianthes Niedenzu (Myrtaceae). Balduinia, n. 22, p. 23-30, 2010.

METCALFE, C. R., CHALK, L. Anatomy of the Dicotyledons. Oxford: Clarendon Press, 1972. $1500 \mathrm{p}$. 
OVANDO, P.C.; LONGHI, E.L.; ROMEIRO, D.; SANTINI JUNIOR, L.; AGUIAR, O.T.; FLORSHEIM, S.M.B.; LIMA, I.L. Anatomia do lenho de Myrcia albotomentosa DC. e Myrcia multiflora (Lam.) DC. (Myrtaceae). $4^{\circ}$ Seminário de Iniciação Científica do Instituto Florestal, 2010.

RECORD, S.J.; HESS, R.W. Timbers of the New World. New Haven: Yale University Press, 1949. 640 p.

RODRIGUES, T.T. Os efeitos do solo contaminado com petróleo na estrutura anatômica e estado nutricional do lenho jovem de Campomanesia xanthocarpa Berg (Myrtaceae) e Sebastiania commersoniana (Baillon) Smith \& Downs (Euphorbiaceae). Tese (Doutorado) - Universidade Federal do Paraná, Curitiba, 2005.

SANTOS, S.R.; MARCHIORI, J.N.C. Caracterização microscópica do lenho de Campomanesia xanthocarpa O. Berg (Myrtaceae). Balduinia, n. 18, p. 10-14, 2009.

SOBRAL, M. A família Myrtaceae no Rio Grande do Sul. São Leopoldo: Unisinos, 2003. 215p.

VLIET, G.J.C. van; BAAS, P. Wood anatomy and classification of the Myrtales. Annals of the Missouri Botanical Garden, n. 71, p. 783-800, 1984. 